\title{
periferio
}

\section{CONTRIBUIÇÕES DAS DIMENSÕES: ESPAÇO, TEMPO E SUJEITO, PARA PENSARMOS O USO DOS DISPOSITIVOS MÓVEIS NA PERIFERIA DO RIO DE JANEIRO}

\author{
Lhays Marinho da Conceição Ferreira ${ }^{1}$ \\ Universidade do Estado do Rio de Janeiro
}

\section{Resumo}

A intensificação da presença das novas tecnologias de comunicação e informação tem alterado significativamente as práticas e relações sociais no mundo contemporâneo, e é esse cenário que orienta a pesquisa de mestrado em curso, com o objetivo de investigar os sentidos atribuídos aos usos de dispositivos móveis na sala de aula. Os questionamentos, feitos neste trabalho, têm como ponto de reflexão a produção cultural dos sujeitos em meio à tecnologia na sala de aula, que enseja práticas culturais com grandes implicações durante o momento da aula. A partir do uso de um ambiente virtual que é um território construído, fluido, imaginado e inventado. Entendo os sujeitos como produtores de cultura, e também como não possuidores de uma identidade fixa, imutável ou integral. Com isso, procuro discutir, investigar e problematizar sobre quem são os jovens/alunos do ensino médio normal do Instituto Estadual Sarah Kubitschek, localizado no bairro de Campo Grande, periferia do município do Rio de Janeiro e quais sentidos são - e podem ser - atribuídos aos usos do celular por ele, no momento da aula. Penso que estes não possuem uma identidade e cultura fixas, a partir das contribuições de Stuart Hall, mas que por transitarem por diversos espaçostempos, por estarem em contato com o meio global a todo o momento, por atuarem neste contexto de globalização, produzem cultura, estabelecem novas relações e desestabilizam o projeto ainda dado de escola, como formadora de um único aluno, e nesse caso como formadora de um mesmo modelo de professor.

Palavras chave: identidade; tecnologia; espaço; tempo; sujeito

\footnotetext{
1 Pedagoga e Mestranda do programa de Pós-Graduação em Educação, comunicação e periferias urbanas, - FEBF/UERJ. lhays.uerj@gmail.com
} 


\title{
periferio
}

\section{CONTRIBUTIONS OF THE DIMENSIONS: SPACE, TIME AND SUBJECT, TO THINK ABOUT THE USE OF MOBILE DEVICES IN THE PERIPHERY OF RIO DE JANEIRO}

\begin{abstract}
The intensification of the presence of the new communication and information technologies has significantly altered the social practices and relations in the contemporary world, and it is this scenario that guides the Master's Research, with the objective of investigating the meanings attributed to the uses of mobile devices in the classroom. The questionings, made in this work, has as a point of reflection the cultural production of the subjects in the middle of the technology in the classroom, that it generates cultural practices with great implications during the moment of the lesson. From the use of a virtual environment that is a territory built, fluid, imagined and invented. I understand the subjects as producers of culture, and also as not possessing a fixed, immutable or integral identity. With this, I try to discuss, investigate and problematize who are the high school students of the Sarah Kubitschek State Institute, located in the Campo Grande neighborhood, in the periphery of Rio de Janeiro, and which meanings are - and can be - attributed the use Of the cell phone by him at the time of class. I think they do not have a fixed identity and culture, based on the contributions of Stuart Hall, but because they move through different spaces, because they are in contact with the global environment at all times, because they act in this context of globalization, They produce culture, Establish new relationships and destabilize the still given project of school, as a single student trainer, and in this case as a model teacher.
\end{abstract}

Keywords: identity; technology; space; time; subject 


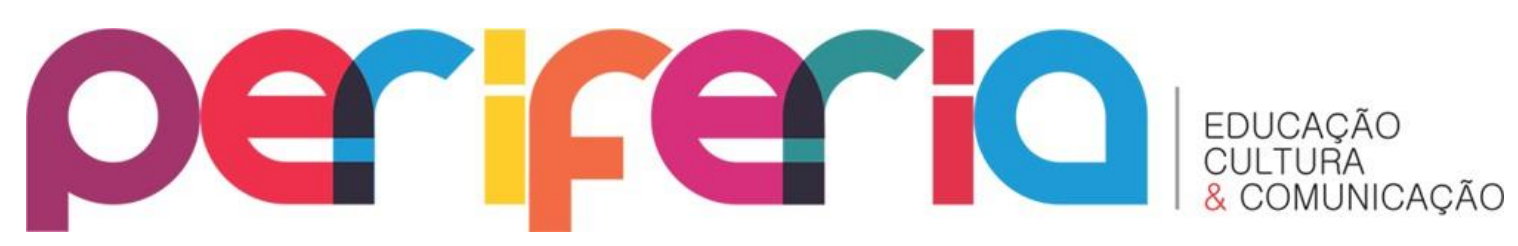

INTRODUÇÃO

Este trabalho tem como objetivo discutir as contribuições das dimensões de espaço, tempo e sujeito para a construção da minha pesquisa, intitulada (provisoriamente) como o lugar do celular na formação das futuras professoras: o caso do Instituto de Educação Sarah Kubitschek, refletindo e problematizando o uso dos dispositivos móveis na periferia da cidade do Rio de Janeiro. A discussão parte das indagações sobre usos da tecnologia no momento da aula, tendo em vista as mudanças ocorridas no cenário social contemporâneo e que reconfigura os processos de produção e a relação com conhecimento, entendendo o conhecimento como produção cultural em constante movimento. Com isso, pretendo refletir a partir dos movimentos e ações que permeiam a escola e que sugerem outras formas de relação dos sujeitos com o mundo e com o outro, nas diferentes dimensões, sociais e econômicas, onde fluxos globais de relações na contemporaneidade permitem outras formas de organização e de produção (ROSÁRIO, 2015).

A partir desse novo contexto global, por meio da globalização, os dispositivos móveis vêm sendo utilizados nas mais diversas áreas e em nosso cotidiano. Esta utilização tem se expandido, pois há o que podemos chamar as gerações anteriores tem se apropriado cada vez mais destas tecnologias, e as novas gerações, já incorporam tais dispositivos como uma extensão do lar ou de seu próprio corpo (SABOIA; VARGAS; VIVA, 2013).

A existência e o uso destas tecnologias não se evidenciam somente no momento em que vemos um dispositivo em uso, mas culturalmente nossas ações, nossas relações e nosso vocabulário denunciam que estamos fortemente influenciados por esta era digital. Os assuntos nas rodas de amigos, os textos escolares, científicos, os namoros entre outras relações sociais não necessitam mais da presença física para que ocorram. A principal característica destes tipos de dispositivos é justamente serem móveis. Esta característica propicia que haja uma imediata atualização da informação, seja das redes sociais, um material específico de curso, assuntos pessoais ou de localização. (SABOIA; VARGAS; VIVA, 2013, p. 04) 


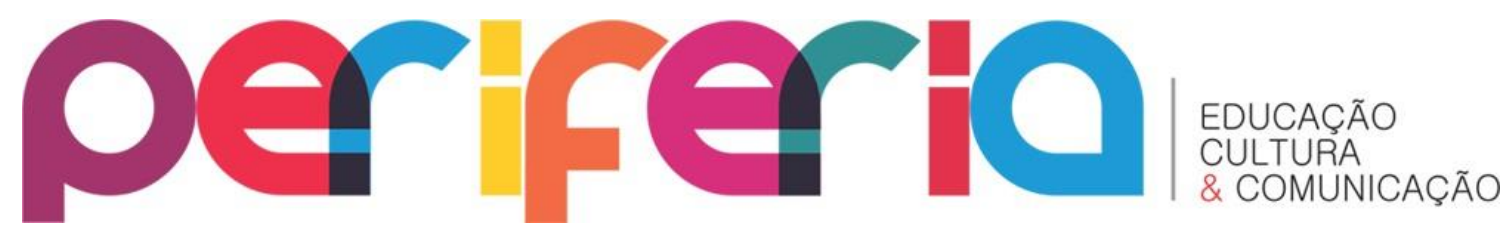

A tecnologia, de uma maneira geral, propicia o surgimento de novas percepções e noções, em que o seu desenvolvimento transforma o modo em que se compreende o tempo e o espaço (MENEZES, 2003 apud SABOIA; VARGAS; VIVA, 2013). Na Era do Conhecimento, a tecnologia possibilita a expressão de novas atividades, novos formatos de interação social, ampliação dos locais, formatos e estrutura do processo de ensino e aprendizagem, ampliando a percepção da sala de aula e da interação aluno-professor e aluno-aluno. (SABOIA; VARGAS; VIVA, 2013)

Em minha pesquisa, focalizo num contexto micro para entender as apropriações que os sujeitosestudantes fazem dessa tecnologia, embora haja a necessidade de entendermos o contexto global ao qual estamos inseridos, neste trabalho trago o contexto local do INSTITUTO SARAH KUBITSCHEK, colégio localizado no bairro de Campo Grande, no município do Rio de Janeiro. Esta instituição atende apenas ao nível médio em modalidade normal, com formação de professores. Trago aqui um panorama para pensarmos o que é este local, qual o meu entendimento de quem são os sujeitos que ocupam esse espaço e como eles podem ou utilizam os dispositivos móveis na sala de aula. Aqui me atento apenas, as dimensões espaciais, temporais e de subjetividade para discutir como vejo este local. Focalizando também na emergência dessas novas tecnologias em relação a esses sujeitos. A percepção sobre como utilizam a tecnologia, será realizada em um próximo momento, na dissertação, ainda em construção.

\section{1 - PENSANDO O LOCAL: O INSTITUTO SARAH KUBITSCHEK}

Pretendo descrever aqui, um pouco sobre o Instituto Estadual (IE) Sarah Kubistschek, reduzindo a escala, não para entendimento da história local, mas como um procedimento analítico, que pode ser aplicado em qualquer lugar, independentemente das dimensões do objeto analisado (LEVI, 1992, p.137). Entendendo que, por meio de uma "pesquisa micro-histórica é a crença em que 


\section{periferio}

a observação microscópica revelará fatores previamente não observados" (LEVI, 1992, p. 139).

O Instituto Estadual (IE) SARAH KUBITSCHEK está localizado no bairro de Campo Grande, no município do Rio de Janeiro. O IE começou a atuar, de acordo com COSTA (2009), nos anos 1950, no bairro Campo Grande que era localizado na chamada Zona Rural do Rio de Janeiro. Esta região era considerada progressista, ainda mais com a inauguração da estação de Campo Grande pela Estrada de Ferro Central do Brasil em 1878. Além desse avanço no transporte, a região nos anos 40 , possuía uma produção de laranjas que superava os outros produtores da cidade. Já nos anos 50 , começa a luta pela educação na região, os políticos queriam soluções para o atendimento escolar e acesso dos professores ao bairro.

Nessa ocasião, o vereador Miécimo da Silva encaminha um projeto para a criação de uma Escola Normal na região, mas após apreciação legislativa se transformou no Projeto-Lei n. 906. Os estudos parlamentares culminaram com a aprovação desse projeto criando a Escola Normal de Campo Grande, oficializada na Câmara no dia 16 de dezembro de 1957. (COSTA, 2009, p. 49)

A escola é inaugurada em 03 de maio de 1959, passa a funcionar em salas alocadas de outra escola municipal, num primeiro momento, no centro de Campo Grande. 0 nome da escola foi uma homenagem à primeira dama brasileira, da época, Sarah Kubitschek, esposa do Presidente da República Juscelino Kubitschek.

Em agosto de 1960, surge então, a sede da Escola Normal Sarah Kubitschek, na Rua Augusto de Vasconcelos, número 212, este prédio não comportava o crescimento da instituição, o que desde a década de 60 do século XX, mobilizou o Governo a procurar um novo espaço. Chagas Freitas, ao assumir o Governo do Estado da Guanabara, acabou por concluir o projeto.

Atualmente o prédio se localiza a Avenida Manoel Caldeira de Alvarenga, n 1203. Aos 14 dias de outubro de 1974, o gigante 


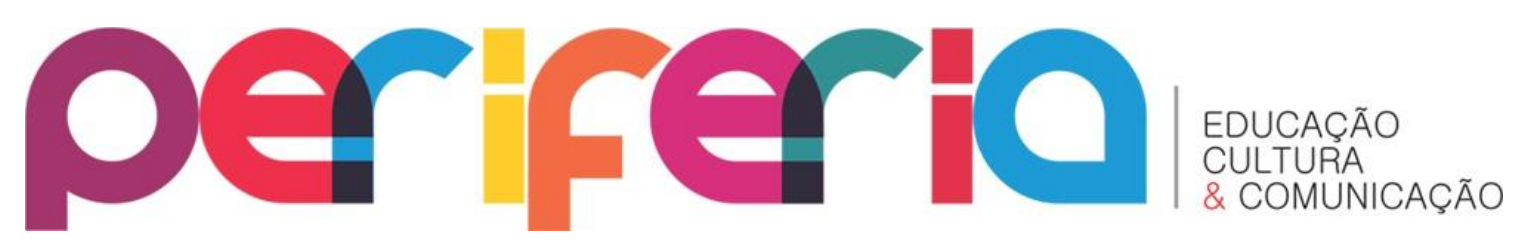

de $44000 \mathrm{~m} 2$, foi consagrado por Chagas Freitas como Instituto de Educação de Campo Grande. Ali passou a funcionar a Escola Normal Sarah Kubitschek e duas escolas de aplicação, uma de educação infantil e a outra de Ensino Fundamental ( $1^{\mathrm{a}}$ a $8^{\mathrm{a}}$ série). A primeira diretora nessa nova etapa foi Dayse Alvarenga. (COSTA, 2009, p.51)

Atualmente, além do curso de formação de professores o prédio também comporta desde 2006 a UEZO (Universidade da Zona Oeste) e uma escola de ensino fundamental.

Figura 1 - IE Sarah Kubitschek

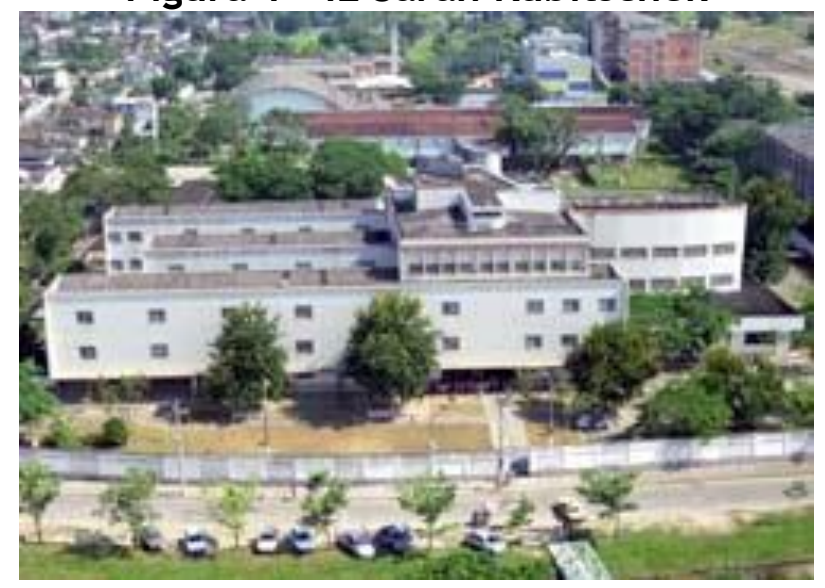

Fonte: http://iesarahkubitschek.blogspot.com.br/ 2007/12/origem-e-localizao.html?m=1

De acordo com o INEP (Instituto Nacional de Estudos e Pesquisas Educacionais Anísio Teixeira), a escola é considerada como localizada em zona urbana, possui acesso à internet com laboratório de informática, biblioteca, cozinha, laboratório de ciências e possui número de matrículas no ensino médio - período que atende - como no quadro a seguir: 


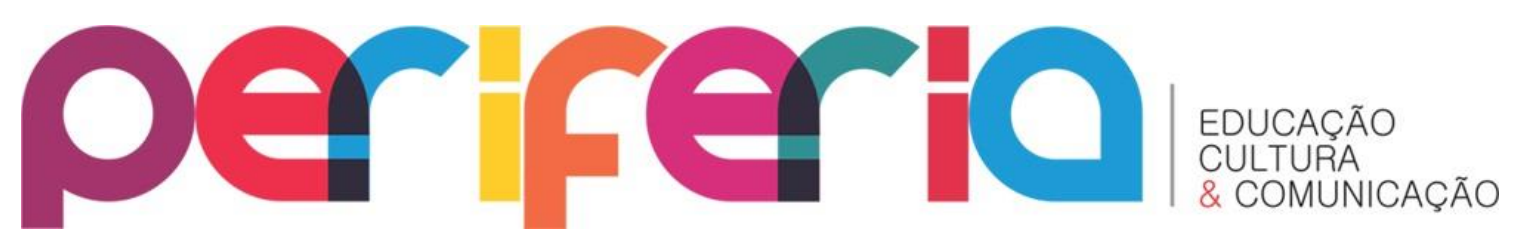

Quadro 1 - Matrículas no Ensino Médio no IE Sarah Kubitschek

Ensino Médio - Número de Matrículas
\begin{tabular}{|l|l|l|l|}
\hline \multicolumn{1}{|c|}{ Menos de 7 horas de duração } & \multicolumn{1}{c|}{7 horas ou mais de duração } & \multicolumn{1}{c|}{ Total } \\
\hline Médio & 616 & 0 & 616 \\
\hline Médio Integrado & 0 & 0 & 0 \\
\hline NormalMagistério & 0 & 1589 & 1589 \\
\hline Total & 616 & 1589 & 2205 \\
\hline
\end{tabular}

Fonte: http://www.dataescolabrasil.inep.gov.br/dataEscolaBrasil/ acesso em 26/12/2016, às 23:45h.

A maioria dos estudantes por ser nível médio, tem idade entre 14 e 18 anos e é de gênero feminino, de acordo com RABELO (2007) a proporção de homens que ingressam nesse Instituto é menor que $10 \%$ da quantidade de mulheres. Percebendo os indícios tanto do local que é marcado por traços “tradicionais" quanto pela marca da história da profissão docente, entendo que não estou preocupada com a interpretação dos significados, mas antes em investigar as ambiguidades do mundo simbólico, a pluralidade das possíveis interpretações desse mundo e a luta que ocorre em torno dos recursos simbólicos (LEVI, 1992, p. 136). Ou seja, as considerações sobre os sujeitos que ocupam este lugar são parte de uma tentativa de retratar o que considero como parte de um mundo representativo, no qual os significados dados também são simbólicos e podem ser reinterpretados por outrem. Aqui estudo este meio social, não como um objeto investido de propriedades inerentes, mas como um conjunto de interrelacionamentos deslocados existentes entre configurações constantemente em adaptação (LEVI, 1992, p. 162).

O IE Sarah Kubitschek está localizado num lugar que “ainda mantém tradições, concepções e valores de uma sociedade de costumes tradicionais, podendo condicionar a construção da identidade do grupo de docentes [...]" (RABELO, 2004, p. 264). O bairro de Campo Grande era considerado um local rural, mas atualmente já possui seu próprio comércio autossuficiente, e se alimenta "de si mesmo", a característica urbana já é perceptível, e com a distância ao centro da cidade, "tudo" pode ser feito no próprio bairro, falo neste momento, como moradora de Campo Grande. Vale ressaltar, a extensão 


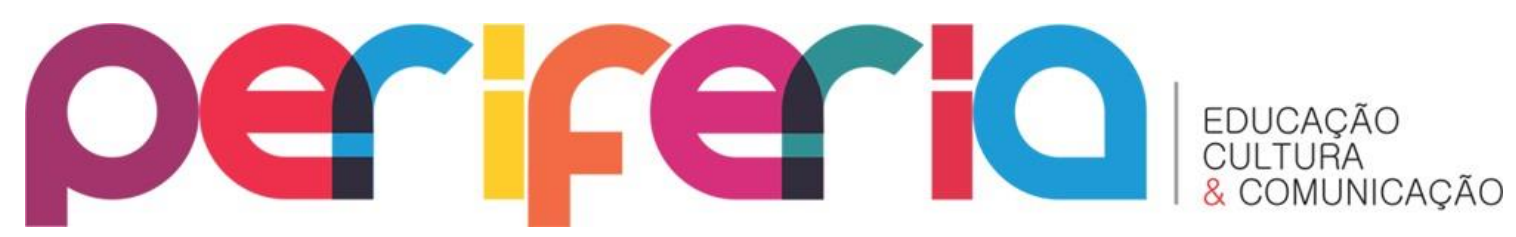

do bairro que possui área de $11.912,53$ hectares, com mais de 328.370 habitantes, e pode ser considerado central na Zona Oeste por sua autonomia e serviços que já oferece. Essas transformações influenciam na construção da memória, identidade e cultura destes futuros professores.

Além disso, suponho que estes jovens, futuros professores e moradores dessa localidade, também possuem dispositivos móveis, como o celular, e que a emergência das tecnologias também chegam a esse espaço, de formas diferentes de outros lugares, talvez por ser na periferia ou no bairro mais populoso da cidade, mas essa emergência também chega ao espaço escolar. Digo isto, pois, em uma primeira conversa com uma professora da coordenação da escola, a qual contribuiu para minha primeira entrada ao campo, foi afirmado que o uso dos dispositivos móveis, principalmente do celular, em todo o período, em que os jovens estão no Instituto, é notório. Então, cabe problematizarmos quem são esses jovens e como $o$ uso destes dispositivos é ou pode ser realizado.

\section{2 - PENSANDO OS SUJEITOS/JOVENS/ALUNOS NO CONTEXTO GLOBAL}

\section{1 - Produção cultural em meio a globalização}

As ações cotidianas dos sujeitos são ações que ocorrem de forma negociada, a partir de práticas discursivas que se instituem. As produções culturais constituídas entre a dinâmica das salas de aula convencional e o uso dos dispositivos móveis, se constituem como um entrelugar de entrelace cultural, havendo uma conexão com o espaço dentro/fora da sala de aula, a partir deste uso. 0 movimento que ocorre entre o real e o virtual cria

outros sentidos e significados para as práticas em sala de aula; a produção do conhecimento não está localizada no espaço físico da sala de aula, muito menos em um tempo específico; ele está sendo produzido em outros espaços e tempos não reguláveis, está no fluxo contínuo. Exatamente nessa percepção de produção dos sujeitos e não mais na transmissão 


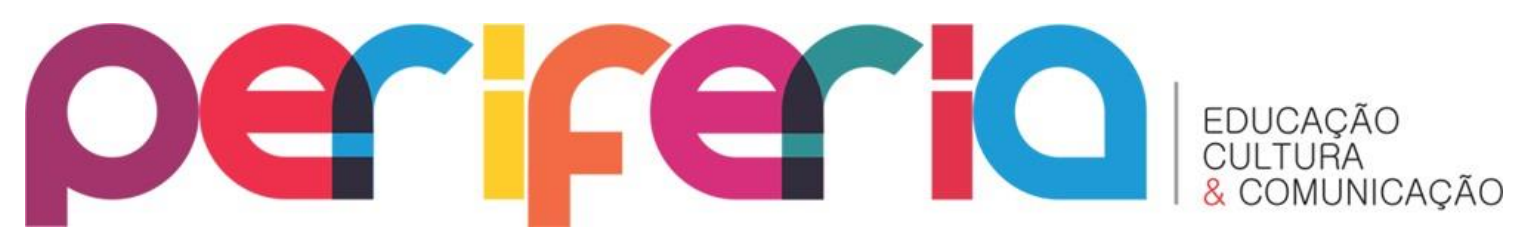

que, se ainda não acontece, exige que se problematize, se afirme a proposição de nossas análises. (ROSÁRIO, 2015, p.12)

A comunicação, as tecnologias e a educação compõem uma relação de grande valia para a formação do homem do século XXI (CORTELAZZO, 1998). Atualmente, a tecnologia estabelece novas condições para que a comunicação social se insira nos espaços de aprendizagem, pois por meio de suas dinâmicas de produção e desenvolvimento do conhecimento, favorece a socialização do saber entre os sujeitos.

Entendo que atualmente há mais intensidade nas interações no sentido global, nacional e local com a chegada das Tecnologias de Informação e Comunicação (TICs), em especial com a chegada da internet. Entretanto, essa interação e globalização não se dá apenas no âmbito econômico, com as TICs a globalização se dá no âmbito cultural também.

As mudanças tecnológicas aproximando os sujeitos no espaço e no tempo, a globalização econômica, o fim da Guerra Fria, os fluxos migratórios são alguns dos ingredientes que criam uma atmosfera favorável ao maior fluxo de pessoas entre culturas. (LOPES e MACEDO, 2011, p. 185)

Neste novo contexto comunicacional e informacional é evidente a emergência das tecnologias no processo de produção cultural, sendo esta também uma produção cultural, pois aqui a consideramos numa perspectiva que a entende como linguagem.

Nessa perspectiva, opero com a ideia de que os recursos tecnológicos estão inseridos enquanto produção cultural na nossa sociedade contemporânea. As mudanças tecnológicas que aproximam os sujeitos em diferentes espaços e tempos, a globalização de informações, são parte de uma realidade que favorece ao maior fluxo de interação entre diferentes maneiras de produção de cultura, que operando com o conceito de zonas de fronteiras, assim como os autores pós-coloniais, entendo que há fluxos culturais e não as culturas. Para Lopes e Macedo (2011) apud Appadurai (2004) 


\section{periferio}

as culturas são estancamentos artificiais dos fluxos, uma espécie de fotografia que paralisa e nomeia o que é puro movimento.

Entendo que a sociedade contemporânea é descrita por meio de diversas culturas, que é evidenciado a partir das inúmeras ações na rede (internet), embora haja uma padronização nos conteúdos, no acesso, e nas redes sociais, cada sujeito que tem acesso age de formas diferenciadas, seja por meio dos posts, das mensagens, dos compartilhamentos e etc, e isto resulta em um movimento que significa a produção cultural. Sabemos a tecnologia é o principal recurso de informação e comunicação em uso na nossa sociedade contemporânea. As mudanças tecnológicas que aproximam os sujeitos em diferentes espaçostempos, a globalização de informações, são parte de uma realidade que favorece ao maior fluxo de interação entre diferentes maneiras de produção de cultura.

Neste contexto global, notamos a centralidade da cultura e do conceito de identidade em relação à globalização, a partir das perspectivas de Stuart Hall (1997), pois ganha espaço na organização das atividades, instituições e relações sociais. A centralidade se dá a partir da globalização, que é facilitada em grande parte pelo progresso tecnológico que encurta distâncias e possibilita a interação instantânea entre sujeitos e culturas, podemos então, afirmar que essa distância é sanada a partir das Tecnologias de Informação e Comunicação. Embora haja aspectos homogeneizadores da globalização sobre a cultura, é impossível haver uma saturação total (HALL, 1997). "Ainda que as culturas locais passem a ser referenciadas a uma cultura global, também se ampliam as possibilidades de comunicação entre elas, possibilitando o fortalecimento de laços locais" (LOPES e MACEDO, 2011).

Para Hall (2006, p.67), a globalização como um complexo de processos e forças de mudança tem poderosamente deslocado as identidades culturais nacionais. Hall (2006) apud McGrew (1992) afirma que a globalização se refere aos processos atuantes numa escala global, que atravessam fronteiras nacionais, que acabam por integrar e conectar comunidades e organizações em novas combinações de espaço-tempo, tornando o mundo mais 


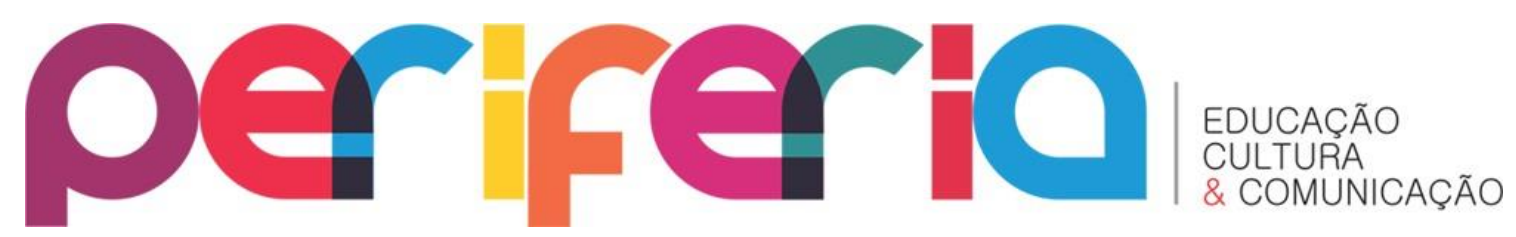

interconectado. Essas novas características temporais e espaciais, que resultam na compressão de distâncias e de escalas temporais, estão entre os aspectos mais importantes da globalização a ter efeito sobre as identidades culturais (HALL, 2006, P.68), ou seja, a partir da globalização há mudanças no entendimento das identidades culturais; as identidades nacionais estão se desintegrando, por haver a homogeneização cultural; as identidades locais estão sendo reforçadas pela resistência à globalização; e, novas identidades híbridas estão tomando o lugar das identidades nacionais, que estão em declínio (HALL, 2006, p. 69).

Hall (2006) irá discutir sobre a compressão espaço-tempo, afirmando que a aceleração dos processos globais, torna o mundo "menor", com distâncias mais curtas, no qual os eventos de um determinado lugar têm impacto imediato sobre pessoas e lugares localizados a uma grande distância. Massey (2000) também irá discorrer sobre essa compressão, afirma que este processo é caracterizado muitas vezes por uma aceleração e superação de barreiras espaciais, e que agora alcançou um novo estágio, do que Marx conceituou de "a aniquilação do espaço pelo tempo", agora temos uma compressão espaço-tempo. “Um dos resultados dessa atuação é a crescente incerteza sobre o que queremos dizer com "lugares" e como nos relacionamos com eles" (MASSEY, 2000, p. 177), defende então um sentido progressista de lugar.

É um sentido do lugar, um entendimento de 'seu caráter', que só pode ser construído por meio da ligação desse lugar com outros lugares. Um sentido progressista do lugar reconheceria isso, sem se sentir ameaçado. Parece-me que precisamos de um sentido global do local, de uma consciência global do lugar. (MASSEY, 2000, p. 185)

Essas noções de pertencimento de um lugar e um território (como vimos sobre o espaço do IE como um lugar de tradições, por exemplo, onde a comunidade é suficiente em si mesma), nos remete a discussão sobre identidade. Mas antes de abordamos sobre o conceito de identidade e o 


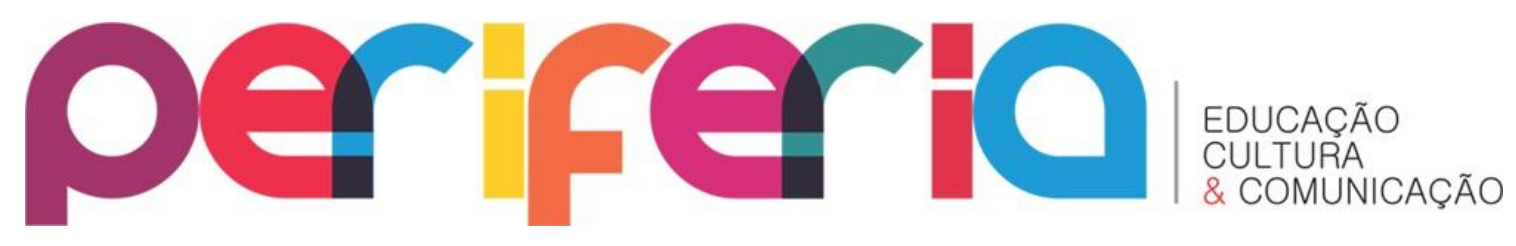

impacto da globalização em relação a ela, devemos pensar como a identidade se insere no circuito da cultura. Hall (1997), afirma que vem correndo uma revolução cultural no sentido substantivo, empírico e material da palavra. Por meio das tecnologias e da revolução da informação, os meios de produção, de circulação e de troca cultural vêm se expandindo. A compressão do tempo e do espaço que as novas tecnologias possibilitam permite mudanças na consciência, pois vivemos em mundos múltiplos e virtuais.

Podemos pensar que a ascensão das TICs, mobiliza a criação de uma teia com sociedades que possuem histórias distintas, diferentes modos de vida, situadas em diferentes fusos horários, etc. Nesse momento, as revoluções da cultura a nível global impactam os modos de viver, o sentido que as pessoas dão à vida, à cultura num sentido mais local. Estas mudanças culturais globais criam uma rápida mudança social, e também deslocamentos culturais. (HALL, 1997).

Entretanto, como afirma Hall (1997), a homogeneização cultural é um efeito para essa compressão espaço-tempo, mas esta revolução cultural global não é tão uniforme como parece, muito menos fácil de ser prevista, ela também é uma característica dos processos que eles sejam distribuídos mundialmente de forma irregular e que as consequências sejam contraditórias.

A cultura global necessita da "diferença" para prosperar, convertendo ou não em outro produto cultural para o mercado mundial. É, então, possível que produza novas identificações globais e novas identificações locais do que uma cultura global uniforme e homogênea. A revolução cultural e da informação provoca novas forças e relações, a cultura passa a ser um processo dinâmico e mais imprevisível (HALL, 1997).

Temos que entender então o impacto que essas revoluções culturais causam sobre as sociedades globais e na vida cotidiana local, a menção do seu impacto na vida interior relaciona-se a centralidade da cultura na constituição da subjetividade, da própria identidade, da pessoa em si como ator social. A identidade emerge, não tanto de um centro interior, de um "eu único"- 


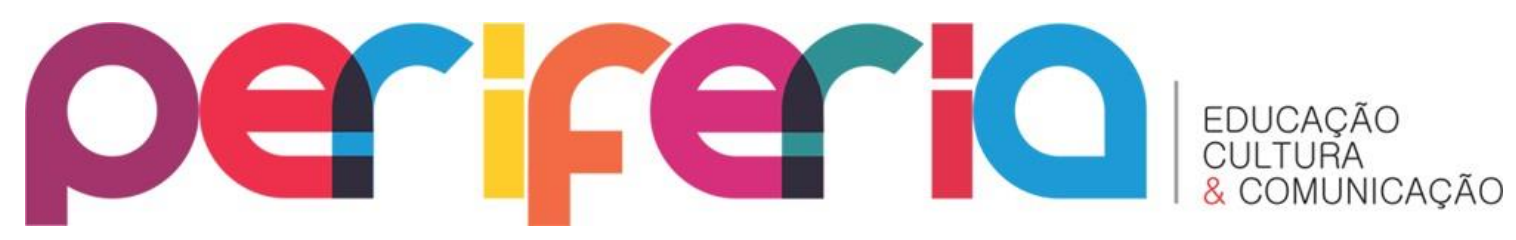

abordarei essa questão do sujeito centrado a seguir -, mas do diálogo entre os conceitos e definições que são representados para nós pelos discursos de uma cultura e pelo nosso desejo de responder aos apelos feitos pelos significados, de assumirmos as posições de sujeito construídas para nós (HALL, 1997).

Poderia conceituar melhor a questão das "nossas identidades", a partir de Hall (1997), como sedimentações por meio do tempo daquelas diferentes identificações que adotamos para viver, que são ocasionadas por diversas circunstâncias, histórias e experiências como sujeitos individuais. Nossas identidades são formadas culturalmente. As identidades sociais são construídas no interior da representação, por meio da cultura, e não fora delas, elas são resultado de processos de identificação que permite que nos posicionemos no interior das definições que os discursos culturais, que são exteriores, fornecem ou que nos identifiquemos e subjetivemos, dentro deles. Então, a partir disso, nossa identidade e subjetividade são produzidas de modo discursivo e dialógico; e com o interesse na cultura, nossa compreensão desse processo é reconstruída. $E$, além disso, quando a cultura intervém, a distinção entre interior e exterior, entre social e psíquico é rompida. (HALL, 1997).

A identidade está ligada ao processo de representação, sendo assim, a moldagem e remoldagem das relações espaço-tempo no interior de diferentes sistemas de representação têm efeitos sobre a forma como as identidades são localizadas e representadas. Dessa forma, "todas as identidades estão localizadas no espaço e no tempo simbólicos” (HALL, 2006, P. 71).

Há então, uma separação entre espaço e lugar, sendo o "lugar" específico, concreto, familiar e delimitado - o ponto de práticas sociais que nos formaram e que nossas identidades são ligadas. Os lugares são fixos, mas o espaço pode ser cruzado, havendo uma destruição do espaço através do tempo. (HALL, 2006, P.72 e 73) Neste movimento de pensar o lugar e o espaço, Hall (2006) recorre a Giddens (1990), que afirma que: 


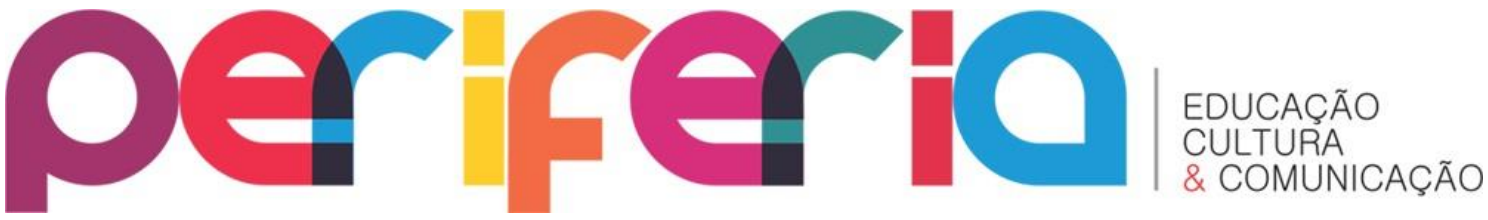

A modernidade separa, cada vez mais, o espaço do lugar, ao reforçar relações entre outros que estão "ausentes", distantes (em termos de local), de qualquer interação face-a-face. Nas condições da modernidade..., os locais são inteiramente penetrados e moldados por influências sociais bastante distantes deles. 0 que estrutura o local não é simplesmente aquilo que está presente na cena; a "forma visível" do local oculta as relações distanciadas que determinam sua natureza (GIDDENS, 1990, p. 18).

Ao refletir sobre essa modernidade que separa o espaço do lugar e que aproxima os ausentes e distantes, para uma relação próxima, reforço a ideia de que a emergência das TICs e das redes sociais, comentadas anteriormente, reforça essa proximidade e altera a interdependência global, mexendo e alterando as identidades culturais, produzindo então, a multiplicidade de estilos, a ênfase no flutuante, na diferença e nos fluxos culturais (HALL, 2006, P.74), que acaba por reforçar a crise do sujeito moderno, descentrado e fluido, que falarei a seguir.

Esses fluxos culturais entre as nações criam possibilidades de identidades partilhadas, mesmo entre pessoas que estão distantes no espaço e no tempo, com a exposição das culturas nacionais às influências externas, a conservação das identidades culturais intactas é dificultada (HALL, 2006, P.74).

\section{2 - Os alunos neste contexto global/local}

Alguns autores conceituam esses jovens que utilizam os dispositivos móveis, assumindo multitarefas, a todo o momento, e em diversos lugares como "nativos digitais". Segundo eles, para estes jovens é habitual fazer duas ou três coisas ao mesmo tempo, como, por exemplo, fazer o download de arquivos, episódios de séries ou filmes, enquanto fazem as tarefas escolares e ainda se comunicam por mensagem de texto, com seus amigos reais e virtuais.

Mark Prensky (2010) considera "nativos digitais" todos aqueles nascidos nos últimos vinte anos, pois nasceram em um mundo completamente tomado 


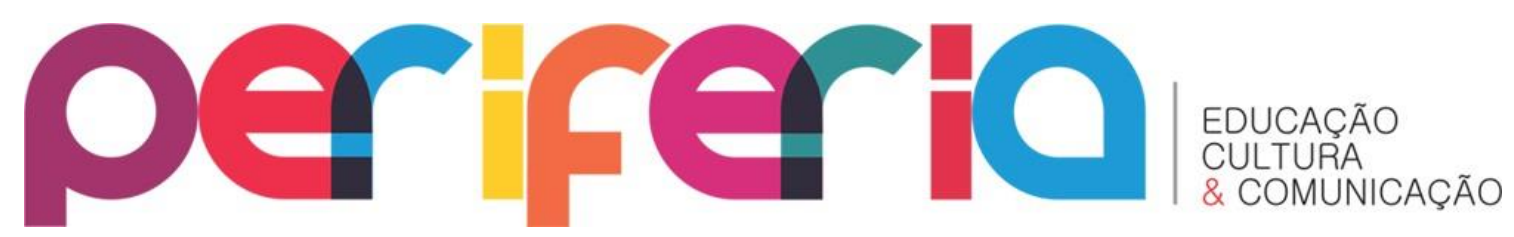

pelas tecnologias de informação e comunicação. As crianças e jovens, que se encontram dentro desse período começam a ter contato com a internet, computadores e games desde sua infância, enxergando estas tecnologias como algo natural a eles. Estes, também são chamados de "geração Y" ou "geração da internet". De acordo com Prensky (2010) os "nativos" são exatamente aqueles pertencentes à geração $\mathrm{Y}$, que convivem desde muito cedo com as mais variadas plataformas digitais. Os “imigrantes" são as pessoas que antecedem as gerações tecnológicas e que, mesmo utilizando os elementos digitais, em nossa concepção, podem ter ou não a mesma habilidade dos nativos. Muitas vezes entendemos os professores como esses imigrantes.

Para o autor, muitos jovens dessa geração obtêm em seu cotidiano informações de forma instantânea e interagem com diversas mídias ao mesmo tempo em função de sua convivência diária com computadores, videogames, áudio e vídeo praticamente desde que nasceram. Além disso, têm o hábito de ficarem constantemente conectados com seus pares, seja através de seus celulares e mensagens instantâneas SMS ou, atualmente, no aplicativo whatsapp e no facebook. Essa geração, como Prensky, destaca, "pensa e processa informações de forma diferente" e sua familiaridade com a linguagem digital faz com que ela seja para eles como uma segunda língua. Os nativos da era digital dão muito valor ao compartilhamento de informações, que é feito geralmente através de blogs e microblogs que podem ser acessados por meio de computadores pessoais ou dispositivos móveis.

Mark Prensky também foi um dos pioneiros a afirmar que o celular deveria ser utilizado em sala de aula, porque se os estudantes levam os seus celulares para a sala de aula porque não utilizá-los em prol do processo de ensino-aprendizagem? Para ele, os celulares possuem o poder de um computador de mesa dos anos de 1990, mas consumindo pouca energia e ocupando menos espaço (PRENSKY, 2010, P.185) Para Martin e Toschi (2014), a posse do celular assegura um pertencimento a um grupo, como se fosse uma identidade da juventude contemporânea, a posse pelos aparelhos eletrônicos é uma marca dessa juventude. 0 celular é uma tecnologia pessoal, fácil de 


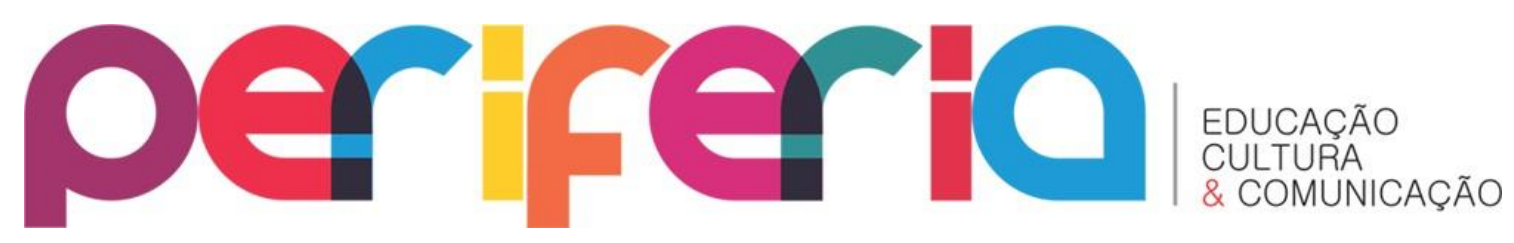

usar que a maioria das pessoas utiliza, porém não é aproveitado para ensinar e aprender na escola (MOURA, 2010, p.9).

Em contraponto, trago meu entendimento sobre esses sujeitos, a concepção teórica que busco a partir das leituras dos estudos culturais, diferentemente destas perspectivas, me faz entender que não podemos denominar e conceituar a cultura jovem como fixa e limitada. Não há uma fixação da cultura jovem, pois consideramos que todos os sujeitos estão inseridos no mesmo espaçotempo ${ }^{2}$, fazem parte desse movimento contemporâneo e estão inseridos nesse fluxo global que está em constante movimento e transformação. Segundo Bauman (2005, p. 35), “as identidades ganharam livre curso, e agora cabe a cada indivíduo, homem ou mulher, capturá-las em pleno voo, usando seus próprios recursos e ferramentas".

Nesta perspectiva, se identificarmos os jovens apenas como pertencentes a uma cultura de nativos digitais, aqueles característicos das zonas rurais ou aqueles que não têm acesso ao computador e aos dispositivos móveis, por exemplo, são excluídos deste movimento contemporâneo. Ou seja, a partir do momento que acreditamos que a cultura é híbrida e ambivalente, na qual todos os sujeitos estão inseridos e produzem cultura e que há um movimento nos fluxos globais onde a cultura é contingencial e está em constante transformação, podemos entender os jovens como produtores de cultura, são produtores não por utilizarem os dispositivos móveis por pertencerem à cultura e fazerem parte do cotidiano deles, mas a partir dos referenciais teóricos, entendemos que os jovens produzem cultura, pois não fixamos e adjetivamos o que ela é, a cultura - como um processo de significação e enunciação - é entendida como uma prática híbrida na qual os sujeitos híbridos a produzem, num processo que é performático e não fixado.

\footnotetext{
Assim como Nilda Alves, opto por usar essas e todas as outras palavras que aqui estão unidas e em itálico para demonstrar a única possibilidade de existência desses termos - um tem relação com o outro e só existe nesta relação. (ALVES, 2001, p.2) Entendendo assim, que estes conceitos se hibridizam e seus significados não podem ser lidos separadamente.
} 


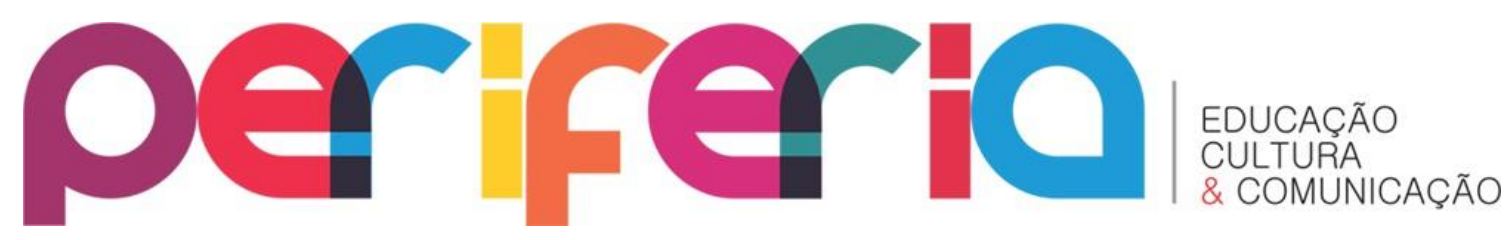

Podemos considerar essa ação social e esta conduta de usar os dispositivos móveis como uma dimensão cultural e discursiva. De acordo com Lopes e Macedo (2011), ao considerarmos a ação social desta maneira, dizemos que a cultura não é somente regulada, mas regula. "Qualquer que seja a ação humana, ela não ocorre fora de sistemas de significados, ela se dá em arranjos de poder discursivo e simbólico". (LOPES e MACEDO, 2011, p.198).

De acordo com Costa (2005, p.96), que estabelece o jovem como exemplo de identidades recriadas de diversas formas, fazendo aparecer novos atores sociais, podemos considerar estes sujeitosestudantes como um "novo tipo de estudantes, com novas necessidades e novas capacidades" (GREEN, 1995, p.209), sujeitos que transitam por diversos espaçostempos, que são integrados, pois nos dispositivos móveis há uma interação constante, estando na fronteira entre o real e o virtual, e isto provêm de movimentos híbridos.

[...] a lógica de interconexão entre os sujeitos e os diferentes espaços, pode ser compreendida como sendo várias "janelas" que se abrem e possibilitam o diálogo que não se limita a um único espaço, mas no trânsito entre eles. Essas janelas, em analogia à possibilidade de abertura e entrada em outros espaços, podem nos apontar uma produção que não se desenvolve de forma linear, mas que se constitui e se situa nas margens deslizantes do deslocamento cultural. (Bhabha, 2010). Dessa maneira, o transitar entre as fronteiras, do real ao virtual, sem que essas fronteiras sejam delimitadoras dos espaços de trânsito dos sujeitos, possibilita aos sujeitos a constituição de suas identidades na relação com o outro e com o mundo, através da linguagem tecnológica. Isso implica perceber que são fronteiras movediças, desestabilizadas por ações conflituosas e também contraditórias. (ROSÁRIO, 2013)

A transição entre o mundo real e o virtual cria outros significados para as práticas em sala de aula; a produção do conhecimento não está localizada no espaço físico da sala de aula, muito menos em um tempo específico; ele está sendo produzido em um fluxo contínuo. Além do entendimento dos sujeitos como produtores de cultura, entendo a categoria sujeito pelo viés da 


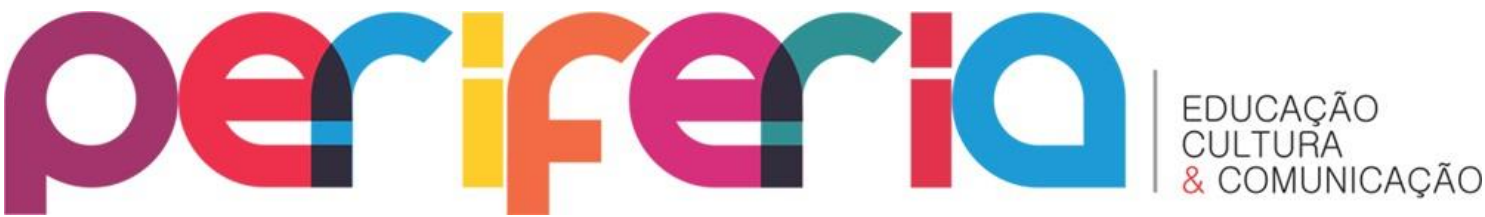

categoria identidade, a partir das contribuições de Stuart Hall, e neste trabalho tomo como base para as discussões essas contribuições. $\mathrm{Na}$ modernidade, de acordo com Hall (2006), havia uma estabilização do mundo social pelas velhas identidades, esta concepção de sujeito unificado está em declínio, surgindo novas identidades e fragmentando o indivíduo moderno. Então, a

[...] chamada "crise de identidade" é vista como parte de um processo mais amplo de mudança, que está deslocando as estruturas e processos centrais das sociedades modernas e abalando os quadros de referência que davam aos indivíduos uma ancoragem estável no mundo social. (HALL, 1992, p.7)

Esta crise de identidade, conceituada por alguns autores, como característica da modernidade tardia e que sua centralidade só faz sentido quando vista no contexto das transformações globais que têm sido definidas como características d ávida contemporânea. A globalização envolve uma interação entre fatores econômicos e culturais, o que causa padrões de produção e consumo que produzem identidades novas e globalizadas (WOODARD, 2012, p.21).

A globalização, entretanto, produz diferentes resultados em termos de identidade. A homogeneidade cultural promovida pelo mercado global pode levar ao distanciamento da identidade relativamente á comunidade e à cultura local. De forma alternativa, pode levar a uma resistência que pode fortalecer e reafirmar algumas identidades nacionais e locais ou levar ao surgimento de novas posições de identidade. (WOODWARD, 2012, p.21)

Considero que, hoje, há uma emergência do entendimento da categoria identidade como não possuindo uma significação única, fixa, imóvel, integral, originária... Essa emergência ocorre pela descentralização e crise do sujeito moderno. As identidades modernas estão sendo descentradas e deslocadas (HALL, 2006, p.8). 


\section{periferio}

Um tipo diferente de mudança estrutural está transformando as sociedades modernas no final do século XX. Isso está fragmentando as paisagens culturais de classe, gênero, sexualidade, etnia, raça e nacionalidade, que, no passado, nos tinham fornecido sólidas localizações como indivíduos sociais. Estas transformações estão mudando nossas identidades pessoais, abalando a ideia que temos de nós próprios como sujeitos integrados. Esta perde de um "sentido de si" estável é chamada, algumas vezes, de deslocamento ou descentração do sujeito. Esse duplo deslocamento - descentração dos sujeitos tanto de seu lugar no mundo social e cultural quanto de si mesmos - constitui uma "crise de identidade" para o indivíduo. (HALL, 2006, p.9)

O que chamo de descentralização (descentração, para Hall) é caracterizado pelas concepções mutantes do sujeito humano e da identidade no pensamento moderno, sendo, este sujeito, percebido como uma figura discursiva (HALL, 2006, p.23). Haveria então, três concepções de sujeito e identidade - sujeito do iluminismo, sujeito sociológico e sujeito pós-moderno que foram sendo alteradas, transformadas durante a modernidade, que explicitarei a seguir, com base em Hall (2006).

O sujeito do iluminismo era baseado numa concepção de centralidade, uma pessoa humana como um indivíduo totalmente unificado, capacitado de razão, consciência e ação, esse centro era um núcleo interior, “o centro essencial do eu era a identidade de uma pessoa” (HALL, 2006, p.11). Era uma visão muito individualista do sujeito.

O sujeito sociológico era um reflexo da complexidade do mundo moderno. Nesta concepção, o núcleo interior do sujeito não era autossuficiente, era construído na relação com outras pessoas importantes para ele, que cambiava os valores, sentidos e símbolos, representados pela cultura, na sociedade que ele habitava. Assim, a identidade é formada na interação entre o eu e essa sociedade. Ainda há uma essência interior, mas é mudada por meio do contato com os mundos culturais e identidades exteriores que esses mundos dispõem. Dessa forma, a identidade preenche o vazio entre o interior e o exterior, entre o pessoal e o público. A identidade 


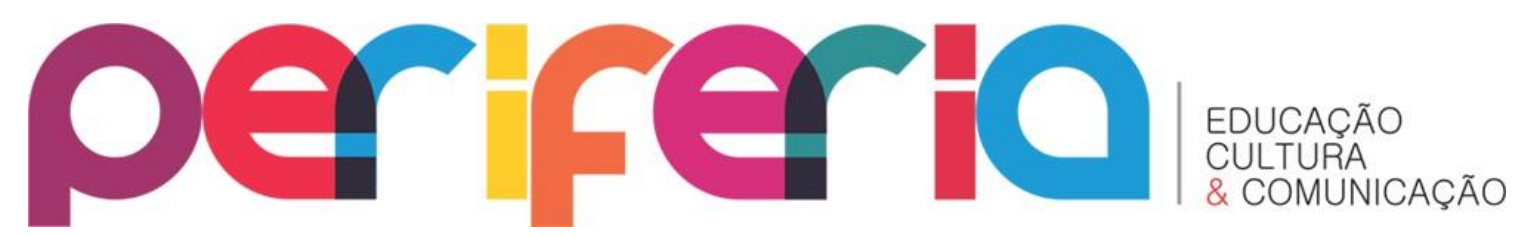

costura o sujeito à estrutura (HALL, 2006, p. 12), tornando os sujeitos e os mundos culturais estáveis e unificados.

A concepção de sujeito como tendo uma identidade única e estável está mudando, o sujeito está fragmentado e é composto por várias identidades. Esse processo de mudança produz o sujeito pós-moderno, este, não tem uma identidade fixa ou essencial. A identidade é definida historicamente, e não pelo viés biológico, ela é transformada continuamente em relação às formas como somos representados nos sistemas culturais.

0 sujeito assume identidades diferentes em diferentes momentos, identidades que não são unificadas ao redor de um "eu" coerente. Dentro de nós há identidades contraditórias, empurrando em diferentes direções, de tal modo que nossas identificações estão sendo continuamente deslocadas. [...] A identidade plenamente unificada, copleta, segura, coerente é uma fantasia. Ao invés disso, à medida em que os sistemas de significação e representação cultural se multiplicam, somos confrontados por uma multiplicidade desconcertante e cambiante de identidades possíveis, com cada uma das quais poderíamos nos identificar - ao menos temporariamente. (HALL, 2006, p.13)

Nas perspectivas do pós-modernismo, o “eu” é inevitavelmente performativo (HALL, 2000), reafirmando a ideia da inexistência do sujeito como puro, único, imutável. Com essa abordagem desconstrutivista, colocamos o conceito de identidade "sob-rasura", sendo reformulada a maneira de pensá-la, pois a forma original (fixa) já não é suficiente para pensarmos na questão da identidade, esse conceito não foi dialeticamente superado, e não há outros que possam substituí-lo, então operamos com ele, sem continuar na lógica do paradigma em que foram elaborados (HALL, 2000, p. 104). Hall afirma que, "a identidade é um desses conceitos que operam "sob-rasura", no intervalo entre a inversão e a emergência: uma ideia que não pode ser pensada da forma antiga, mas sem a qual certas questões-chave não podem ser sequer pensadas" (2000, p.104). 


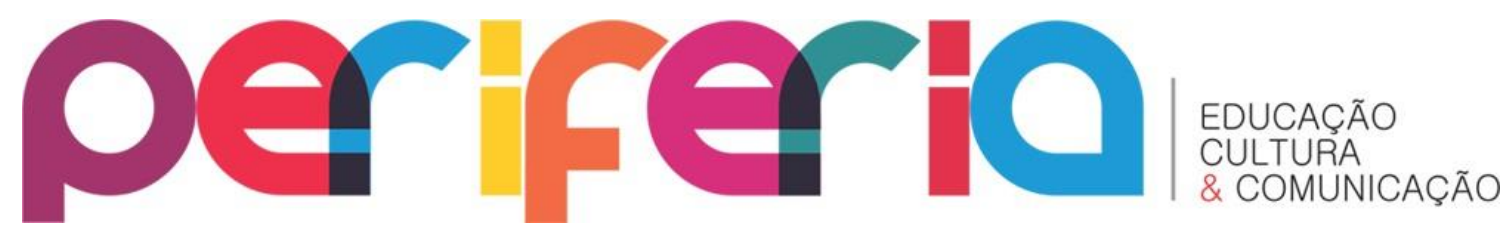

Ou seja, a identidade é formada ao longo do tempo, por meio de processos inconscientes, e não como algo inato, existe na consciência no momento do nascimento. Ela permanece sempre em processo e sendo formada constantemente, embora ainda nos remeta a certa origem - do nascimento.

A identidade surge não tanto da plenitude da identidade que já está dentro de nós como indivíduos, mas de uma falta de inteireza que é "preenchida" a partir de nosso exterior, pelas formas través das quais nós imaginamos ser vistos por outros. [...], nós continuamos buscando a "identidade" e construindo biografias que tecem as diferentes partes de nossos eus divididos numa unidade porque procuramos recapturar esse prazer fantasiado da plenitude. (HALL, 2006, p.39)

Dessa maneira, não falamos de identidade como algo acabado, e então, falamos de identificação, sendo vista como um processo, sempre em andamento (HALL, 2006, p.38-39). Esta definição, de identificação como uma construção e como algo sempre em processo, se dá através de uma abordagem discursiva. A identificação é condicional e alojada na contingência e estando assegurada, não anula a diferença (HALL, 2000, p.106).

“A identificação é um processo de articulação, uma suturação, uma sobredeterminação, e não uma subsunção” (HALL, 2000, p. 106). Dessa forma, sempre terá uma falta, nunca havendo uma totalidade. E sendo estabelecida por um processo, a identificação opera através da différance, envolve a discursividade, e então para concluir o processo,provisoriamente, ela necessita do que ficou excluído, e este exterior também a constitui.

Hall (2000) não sugere que haja uma substituição do termo identidade por identificação, mas reforça, que pelo movimento da modernidade tardia ou pós-modernidade, este termo está recebendo novos significados. Sendo que essa “nova” concepção não se refere àquele eu idêntico a si mesmo ao longo do tempo, puro, fixo, e também não se refere a uma identidade cultural única e coletiva, que garanta um pertencimento cultural que sobreponha a todas às diferenças. Mas por meio desta concepção, assumimos que as identidades 


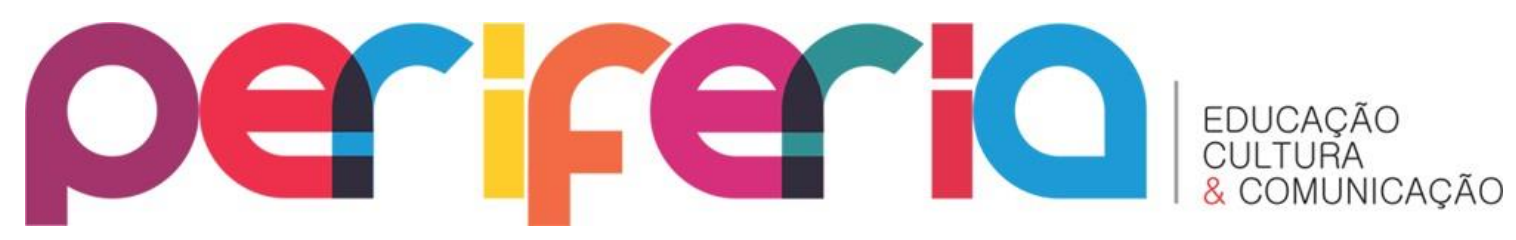

nunca são unificadas, mas que na modernidade tardia, são fragmentadas, são multiplamente construídas ao longo dos discursos que podem ser antagônicos.

\section{CONSIDERAÇÕES FINAIS}

A partir dessa abordagem, assumimos então, que não é possível, falarmos de uma única identidade da escola, do professor, do aluno... Não é possível significarmos de forma totalizante aquilo que entendemos sobre educação, na intenção de justificarmos as implementações de certos projetos curriculares, focalizando em uma "forma" (ou até fôrma) de aluno, um tipo de escola, para um tipo de professor, tendo uma "racionalidade pedagógica pautada pelo estabelecimento de objetivos padronizados" (PEREIRA, ARAÚJO, 2010, p.1075), competências e habilidades à priori.

Conceber a educação como uma prática social implica assumir a centralidade da cultura para pensar os processos relacionados aos processos de escolarização em uma perspectiva que aponte para o reconhecimento da diferença, rompendo com práticas homogeneizadoras, ainda que estas possam ter como pressuposto a construção de um ideal de igualdade social. Práticas que, a nosso ver, têm sido intensificadas nos processos de execução de políticas que objetivam a melhoria dos níveis de desempenho dos(as) estudantes. (PEREIRA e ARAÚJO, 2010, p.1075)

Os processos de identificação e entendimento sobre cultura ao qual discorri aqui, em meu entendimento, fazem com que o modelo de escola atual, como esse projeto da modernidade - com conhecimentos préestabelecidos, carteiras enfileiradas, diferença como algo que compõem, mas que não é levado em consideração, conhecimento e propostas que abarcam apenas um modelo de estudante, que tem a "identidade estudantil" - seja rompido, discutido e repensado. Pois se os estudantes não possuem uma única identidade e cultura, porque ainda pretendemos estabelecer apenas um único 


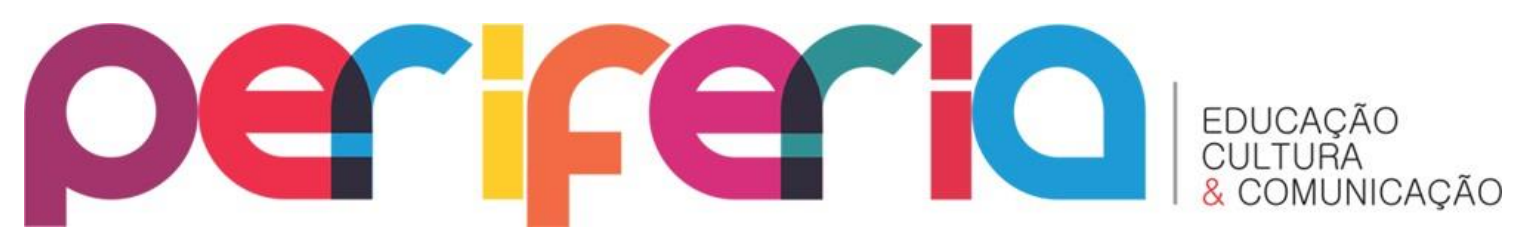

projeto curricular? Faz sentido pensarmos em um modelo de projeto para todas as escolas?

Essa lógica de escola que assume o sujeito que possui sua autonomia de forma cartesiana, acaba por possibilitar uma concepção objetivada de cultura, que, incorporada aos critérios de legitimação mecanicistas, the alçaria ao status de universalidade, nessa perspectiva que temos de escola na qual a identidade idealizada é definida, "em função do objetivo de formá-la a instituição se organiza, criando impedimentos para emergência de alternativas identitárias possíveis. Silenciando as diferenças, ou, no máximo, reconhecendo-as, desde que subordinadas à particularidade definida como ideal." (PEREIRA e ARAÚJO, 2010, p. 1076). Mas estes processos de silenciamento são negociados e traduzidos.

Pensar a cultura como processo dinâmico, imprevisível, nos remete a concepção de cultura de Bhabha (1998) que trata a cultura como processo de significação, onde destaca os processos híbridos pelos quais as culturas se constituem. Homi Bhabha aborda o conceito de hibridismo cultural e define, neste contexto, cultura como prática de enunciação. Assim, não há fixação nos sentidos de uma cultura; sempre que lidos, os sentidos são reapropriados e, a leitura também é enunciação. Dessa forma, há apenas produção na/de cultura e igualmente há sentidos apenas híbridos. Entendo, então, os sujeitos que estão nesses processos como sujeitos híbridos em seus pertencimentos culturais, capazes de produzir novos híbridos.

Bhabha também propõe que a cultura são sentidos produzidos na ambivalência que reitera e nega ao mesmo tempo, então a cultura é sempre híbrida. 0 hibridismo cultural considera então, que as culturas são sistemas de significação que se propõe a fechar os sentidos, mas não os fazem totalmente, elas são espaços-tempos de produção de sentidos, por não existirem de forma fixada (BHABHA, 1998) A partir disso, como afirmam Ferreira e Rosário (2015, p. 02): "não discutiremos [...] numa perspectiva de cultura estanque, mas sim em movimento, em que os sujeitos produzem com elementos que não são 


\section{periferio}

antigos ou novos, mas são um outro, pois possuem características do "antigo" e do "novo"".

Neste mundo pós-moderno, contemporaneo, globalizado, há uma abundância de fatos e contingências, numa realidade plural, densa, plurilocalizada, composta de referências e virtualidades que se cruzam. Neste tempo, o qual nos referimos há num "movimento exploratório incessante, que o termo francês au-delà capta tão bem - aqui e lá, de todos os lados, fort/da , para lá e para cá, para frente e para trás" (BHABHA, 1998, p.19), havendo um "cruzamento de figuras" e imagens, somado às referidas abundâncias dos nossos tempos (MARTINS, 2011). Esta nova forma de conceber o tempo e o espaço, e a nova concepção de identidade como processo de identificação e a cultura como processo de significação e de produção híbrida, que tentei discutir brevemente aqui, dá outro sentido à dinâmica cultural, que acaba por caracterizar a escola. Fornecendo outros elementos que dão novos significados às práticas escolares. (PEREIRA e ARAÚJO, 2010, p.1079)

\section{REFERÊNCIAS}

BHABHA, H. O local da cultura. Belo Horizonte: Ed. UFMG, $5^{\text {a }}$ reimpressão, 2010.

COSTA, Luiz Fernandes da. Curso normal médio: representações sociais de formação por professores e alunos. / Luiz Fernandes da Costa. - Rio de Janeiro, 2010. 102 f. Dissertação (Mestrado em Educação) - Universidade Estácio de Sá, 2009

FARIA FILHO, Luciano Mendes de. História da Educação e História Regional: experiências, dúvidas e perspectivas. In: MENDONÇA, Ana Waleska Campos Pollo et al.(Orgs.). História da Educação: desafios teóricos e empíricos. Niterói, Editora da Universidade Federal Fluminense, 2009.

FERREIRA, L.M.C; ROSÁRIO, R. S. L. Tecnologia e currículo: o uso do celular pelos jovens na sala de aula como produção cultural. In: IV Colóquio Internacional Educação, Cidadania e Exclusão: Didática e Avaliação. 2015. Rio de Janeiro. Disponível em

\&lt;http://www.editorarealize.com.br/revistas/ceduce/trabalhos/TRABALHO 


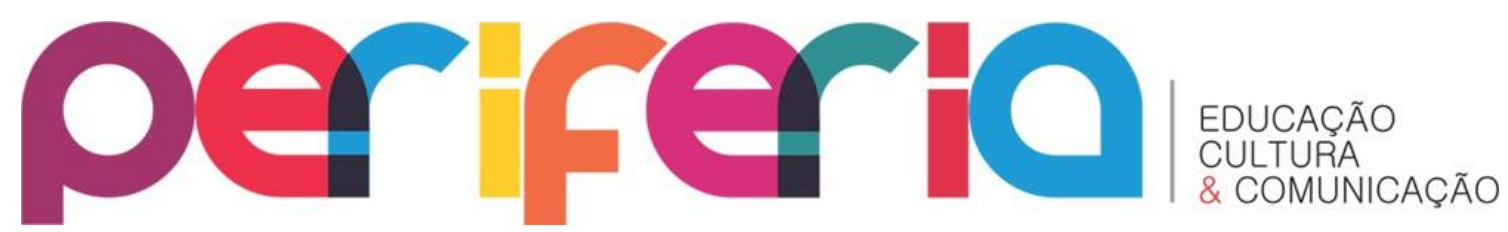

EV047_MD1_SA6_ID799_21052015212033.pdf \&gt; Acesso em 20 de agosto de 2016.

HALL, Stuart. Quem precisa da identidade? In: SILVA, Tomaz Tadeu (org. e trad.). Identidade e diferença: a perspectiva dos estudos culturais..

Petrópolis: Vozes, 2000. p. 103-133.

- A Centralidade da cultura: notas sobre as revoluções culturais do nosso tempo. Revista Educação \& Realidade, Porto Alegre, v.22, p.15-46, jul./dez. 1997.

2006.

A identidade cultural na pós-modernidade. DP\&A: Rio de Janeiro,

LEVI, Giovanni. Sobre a micro-história. In: BURKE, Peter (org.). A escrita da história. Novas perspectivas. São Paulo; UNESP, 1992.

LÉVY, Pierre. As tecnologias da inteligência. O futuro do pensamento na era da informática. Rio de Janeiro: Editora 34, 1993.

A Inteligência Coletiva. São Paulo: Loyola, 1998.

Cibercultura. São Paulo: Editora 34, 2000.

LOPES, Alice Casimiro. Teorias de Currículo / Alice Casimiro Lopes, Elizabeth Macedo. - São Paulo: Cortez, 2011. Apoio: Faperj

MACEDO, Elizabeth. Currículo, Cultura e diferença: o caso da Multieducação com ênfase nas ciências - projeto de pesquisa. Rio de Janeiro, 2008.

- Currículo como espaço-tempo de fronteira cultural. Revista Brasileira de Educação, Rio de Janeiro, Rev. Bras. Educ. vol.11 no.32 Rio de Janeiro May/Aug. 2006

. Currículo: Política, Cultura e Poder. In: Currículo sem Fronteiras, v.6, n.2, pp.98-113, Jul/Dez 2006.

MASSEY, Doreen. Um sentido global do lugar. In: ARANTES, Antonio A. (ORG.) O espaço da diferença. Campinas, SP:2000.

PEREIRA, Talita Vidal; ARAÚJO, Teresa Cristina Oliveira. Aspectos culturais do cotidiano das escolas públicas do município do Rio de Janeiro (Brasil). In: IX Colóquio sobre questões curriculares/ V Colóquio Luso Brasileiro, 2010, Porto. Debater o currículo e seus campos- Políticas, fundamentos e práticas., 2010. p.1075 - 1084.

PRENSKY, M. Não me atrapalhe, mãe - Eu estou Aprendendo! São Paulo: Editora Phorte, 2010. 


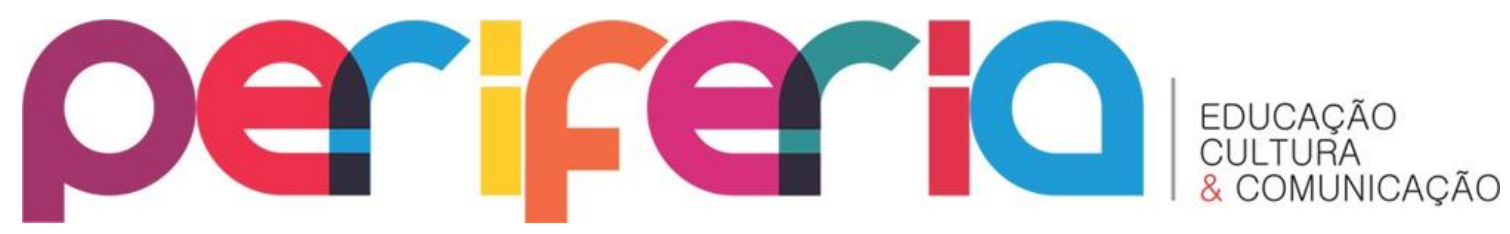

. Aprendizagem baseada em jogos digitais. São Paulo: Senac, 2012.

RABELO, Amanda O. As influências do espaço do Instituto de Educação Sarah Kubitschek (IESK) na memória das normalistas: entre a tranqüilidade e o "feudo". V. 05. N. 10, abr./jun. de 2004.

RABELO, Amanda O. O gênero e a profissão docente: impactos na memória das normalistas. Revista Ártemis. Vol. 6, junho 2007, PP. 58-67.

REVEL, Jacques. Microanálise e construção do social. In: REVEL, Jacques. Jogos de escalas: a experiência da micro análise. Rio de Janeiro: FGV, 1998. 